\title{
Intercambio lingüístico español-neerlandés: \\ Período bajo la Corona Española (1496-1714) de los Países Bajos Históricos
}

\author{
Francisco Sánchez Romero \\ Universidad de Sevilla \\ blacktulyp@hotmail.com \\ https://dx.doi.org/10.12795/futhark.2011.i06.12
}

\begin{abstract}
Los primeros contactos políticos entre España y los Países Bajos históricos comienzan con el matrimonio entre Felipe el Hermoso y Juana la Loca (1496). En el año 1648 los Países Bajos históricos del norte (lo que actualmente son los Países Bajos) se independizan de la Corona española. Sin embargo, el sur (Flandes) se mantiene bajo influencia española hasta el año 1714. En este marco histórico, el español peninsular y el neerlandés intercambian préstamos lingüísticos.

Clasificaré los préstamos en los diferentes campos semánticos para llegar a la conclusión de cuál es el campo semántico que más ha influido en ambas lenguas en este período. A partir de esta ordenación semántica se podrá reconstruir en líneas generales el grado de contacto en diferentes ámbitos del neerlandés con la lengua española. No hay que olvidar que en este período analizado España se asienta en el continente americano, lo que hará que el español de América también influya directamente con préstamos en la lengua neerlandesa. Por lo tanto, también se recogerán en el presente estudio.
\end{abstract}

Palabras clave: neerlandés; préstamos; etimología; campos semánticos; lexicología

Abstract: The first political contacts between Spain and the historical Netherlands begin with the marriage between Philip the Handsome and Juana la Loca (1496). In 1648, the historical northern Netherlands (the current 
Netherlands) becomes independent from the Spanish Crown. However, the south (Flanders) remains under Spanish influence until 1714. Within this historical frame, Dutch and Peninsular Spanish exchange loanwords.

The loanwords will be classified into different semantic fields. This way, it will become clear which semantic field has influenced both languages the most during this period. This semantic classification will be the starting point to enable the basic reconstruction of the degree of contact between Spanish and Dutch in different fields. It is important to mention that Spain is based on the American continent during this period. Hence, American Spanish will also be a direct influence on Dutch. Therefore, they will be part of this study too.

Keywords: Dutch; loanwords; etymology; semantic fields; lexicology

\section{Los contactos directos entre la España peninsular y los Países Bajos históricos}

Las relaciones entre los Países Bajos históricos y España se hacen más intensas y directas a consecuencia del matrimonio entre Felipe el Hermoso y Juana la Loca (1496). A partir de esta fecha, ambos países comparten diferentes reyes españoles hasta el año 1648. En el año 1504, Juana la Loca heredaría el trono de Castila después de la muerte de su madre Isabel. De este modo, Felipe el Hermoso se convirtió en el soberano de un imperio mundial que además de los Países Bajos y de los territorios en Borgoña abarcaría España, Sicilia, Cerdeña, Nápoles y Austria, y también todos los territorios descubiertos en el Nuevo Continente.

Felipe el Hermoso, en su primer viaje a España, trajo más de 300 nobles, capellanes y criados flamencos. Pero la corte española y sus costumbres también influyen en los Países Bajos históricos, ya que los nobles y los señores españoles se establecen en las ciudades, sobre todo en Amberes tras la caída de esta ciudad en 1585. De este modo se recogen los siguientes títulos honoríficos: don <esp. don, infante <esp. infante. Con respecto a la vestimenta utilizada por la corte se registra el préstamo pollevij 'tacón del zapato' <esp. poleví. Hoy en día todavía se utiliza este término con un uso regional en Flandes. Asimismo, por la influencia de las fiestas cortesanas, aparece el préstamo español maskerade 'fiesta de enmascarados' <esp. mascarada. 
En 1515 Carlos V gobernaba los Países Bajos. Tras la muerte de Fernando el Católico en 1516, se proclamó rey de Castilla. Durante la última parte de su reinado tomó medidas para evitar la propagación de las doctrinas protestantes. La intensificación de la lucha en los Países Bajos contra el protestantismo por parte de su hijo y rey español, Felipe II, la continua presencia de las guarniciones españolas y el envío del duque de Alba para sofocar la rebelión hacen que se inicie la guerra hispano-neerlandesa en 1568, denominada en neerlandés de Tachtigjarige Oorlog (1568-1648) ${ }^{1}$. Geoffrey Parker afirma que con el envío del duque de Alba y una tropa de 10.000 soldados españoles a Bruselas en 1567 se produce la transformación de la organización política y militar en Flandes. ${ }^{2}$ Así, en el campo semántico de la política observamos en español el término estatúder que proviene del neerlandés stadhouder, que es una palabra compuesta de stad (lugar, ciudad) y houder (teniente). Era un jefe o magistrado supremo de la antigua República de los Países Bajos. Al contrario, en neerlandés, se registra el préstamo español alcalde <esp. alcalde.

Los conflictos y guerras entre ambos países originan que haya un intercambio de vocabulario relacionado con el campo semántico militar. Durante la mayor parte de la guerra de los Ochenta Años el contingente español ascendió a 65.000 soldados. Así, en la lengua neerlandesa se registran los siguientes préstamos españoles en los que la mayoría se refieren a rangos militares: kornel <esp. coronel, majoor <esp. mayor (es una abreviatura de sergeant-majoor) y alferes <esp. alférez; arsenaal <esp. arsenal y commando 'una orden' <esp. comando, que deriva de comandar (hoy mandar). ${ }^{3}$ Se registra también un préstamo histórico en el siglo XX cuyo contexto se enmarca en el período estudiado en este artículo: tercio (1926-50) <esp. tercio.

\footnotetext{
${ }^{1}$ Se recoge en la historia española como 'la guerra de los Ochenta Años' o también como 'La Guerra de Flandes'.

${ }^{2}$ Geoffrey Parker, El ejército de Flandes y el Camino Español 1567-1659, Madrid: Alianza Editorial, 2003, pág. 143

${ }^{3}$ La acepción de 'grupo armado' no se registra en las lenguas europeas hasta el siglo XIX cuando el inglés lo recoge a través del afrikáans. Una serie de comandos 'grupos de colonos neerlandeses armados' lucharon contra los ingleses en Sudáfrica. Posteriormente la palabra comando se hizo muy popular entre los británicos durante la Segunda Guerra Mundial. Vid. VVAA, Etymologisch woordenboek van het Nederlands, Amsterdam: Amsterdam University Press, 2003, vol. A-E, pág. 463.
} 
Como consecuencia de la caída del puerto de Amberes en 1585, el comercio y la flota neerlandesa se trasladaron a ciudades como Róterdam y Ámsterdam, lo que originó el refuerzo de la unidad nacional de los Países Bajos, que acabó convirtiéndose en una gran potencia naviera y económica (poseían más de 12.000 barcos de mercancía en el siglo XVII, el triple que Inglaterra). Tras la paz de Münster (1648) y el declive del Imperio español, los Países Bajos e Inglaterra se convierten en las primeras potencias mundiales, dominando comercialmente la mayoría de los mares. El hecho de que España no pudiera mantener una flota en el mar del Norte fue quizás decisivo para no poder dominar los Países Bajos, ya que por tierra la victoria era mucho más difícil. Los Países Bajos históricos del norte vivirán una etapa de prosperidad a partir del siglo XVII, denominada en neerlandés De Gouden Eeuw 'EI Siglo de Oro', debido a dos motivos fundamentalmente: la huída de intelectuales de Amberes hacia el Norte, tras la caída de esta ciudad (1585) en manos españolas y la independencia de los Países Bajos del Norte con respecto a la corona española. El número de personas total que huyó a las Provincias Unidas del Norte se calcula en unas 100.000. ${ }^{4}$

Los Países Bajos históricos estaban formados por una red interior de canales que conectaba con el océano Atlántico. Por los ríos Elba, Weser, Rin, Mosa y Escalda pasaban al interior los productos que traían de todo el mundo. Las materias primas procedentes del comercio con países del Báltico y el mar del Norte sirvieron a los neerlandeses para construir barcos más baratos, sobre todo los llamados fluits. ${ }^{5}$ Estos tenían una mayor capacidad de carga, eran más ligeros y tenían una tripulación menor, lo que abarataba los costes. A este precio ningún país del mundo podía competir y se crea un monopolio del comercio marítimo.

Todo esto tiene repercusiones en el comercio con España. La ruta marítima entre los puertos cantábricos y vascos y los de las costas flamencas y holandesas fue una de las más cortas del comercio. Bastaban unos diez o doce días para efectuar la travesía. Un viaje por tierra a través de España duraba mucho más debido a las montañas y la

${ }^{4}$ Roland Baetens, «El desarrollo social y económico de Flandes durante los siglos XV, XVI y principios del S.XVII», En: Encuentros en Flandes, Leuven: Leuven University Press, 2000 , pág. 75.

${ }^{5}$ Cfr. Jonathan I. Israel, De republiek 1477-1806, Franeker: Van Wijnen, 2001, pág. 124. 
deficiente infraestructura viaria. A Brujas acudían los mercaderes españoles a vender sus prestigiosas lanas de ovejas merinas y el hierro de Vizcaya, comprando a su vez telas flamencas y encajes de Brujas. Como consecuencia de la ruptura del comercio anglo-flamenco, la importancia de la lana española creció. Se hicieron famosos en España los paños de sarga procedentes de Flandes. ${ }^{6}$ A partir de 1430 la exportación fue subiendo hasta que en el siglo XVI se vendían una media de 20.000 sacos de paños al año. Dos flotas de diez a veinte barcos al año se encargaron del transporte de la mercancía desde Bilbao y Laredo. Se calcula que en el siglo XVI residían unos 300 mercaderes españoles en la ciudad de Amberes. Para competir en el comercio internacional, los cántabros habían constituido la Hermandad de las Cuatro Villas -Castro Urdiales, Laredo, Santander y San Vicente de la Barquera. Los Países Bajos se convirtieron en una potencia naval aportando a las naciones europeas, incluida España, un gran conocimiento del mar, la navegación y la pesca. Los préstamos neerlandeses referidos al campo semántico de la navegación que se registran en la lengua española son los siguientes:

- arrumar 'distribuir y colocar la carga en un buque' <neerl. ruim. En neerlandés el término ruim 'espacio' también tiene como acepción el espacio interior debajo de la cubierta de un barco. ${ }^{7}$ Sin embargo, Joan Coromines no ofrece un origen neerlandés, sino francés. ${ }^{8}$

- botequín 'barquito' <neerl. bootkin. Es un vocablo que no se recoge ni en el DRAE ni en el Diccionario crítico etimológico castellano e hispánico. Sólo se localiza en el Diccionario de uso del español, aunque menciona que el término está anticuado. ${ }^{9}$

6 Cfr. Werner Thomas/ Eddy Stols, «La integración de Flandes en la Monarquía Hispánica», En: Encuentros en Flandes, Leuven: Leuven University Press, 2000, pág. 28.

7 Cfr. VVAA., Groot Woordenboek der Nederlandse Taal op CD-ROM. Plus versie 1.0., Utrecht/Antwerpen: Van Dale, 2000.

8 Joan Coromines / José A. Pascual. Diccionario crítico etimológico castellano e hispánico, 1a ed., Madrid: Gredos, 1991-1992, Vol. I, pág. 355.

${ }^{9}$ María Moliner, Diccionario de uso del español en CD-ROM, Madrid: Gredos, 2007.

Futhark 6 (2011)

Sánchez, Intercambio Lingüístico,

225-253

ISSN 1886-9300 
- dogre <neerl. dogger. Es una embarcación parecida al queche y destinada a la pesca en el mar del Norte.

- escaparate 'armario' <neerl. medio schaprade. Joan Coromines aclara que el término neerlandés schaprade es un compuesto formado por dos partes: schapp (estante, armario) y rade, palabra frisona que corresponde al neerlandés reden (preparar). ${ }^{10}$ Se refiere a un tipo de mueble que se encuentra en los buques y que fue prestado al español durante la guerra de Flandes. Hoy en día en español el significado se ha ampliado y se ha perdido el sentido original como término náutico. En neerlandés se recoge actualmente como schapraai.

- eslora longitud de la cubierta de una nave' <neerl. sloerie. Actualmente ya no se utiliza en neerlandés estándar el término sloerie, sino scheepslengte.

- foque 'un tipo de vela' <neerl. fok y galga 'un tipo de cabo' $<$ neerl. galg.

- pichelingue <neerl. Vlissingen. Según el Diccionario crítico etimológico castellano e hispánico ${ }^{11}$, el autor E. Sluiter demostró convincentemente que la ciudad holandesa de Vlissingen llegó a designar a finales del S. XVI a los piratas holandeses, y en el siglo XVIII a los piratas en general. Su origen, por lo tanto, sería onomatopéyico por la pronunciación errónea española de esta palabra. Esta última teoría es confirmada también por B.E. Vidos que aclara que el autor Alonso Vázquez tradujo en sus obras las ciudades de Vlissingen y Bergen op Zoom respectivamente por Pechelingas y Bergas Olzon. ${ }^{12}$ Según el investigador neerlandés

\footnotetext{
${ }^{10}$ Joan Coromines / José A. Pascual. Diccionario crítico etimológico castellano e hispánico, op. cit., Vol. II, 1991-1992, pág. 674.

${ }^{11}$ Ibíd., Vol. IV, pág. 529.

12 Benedek Elémer Vidos, «Relaciones antiguas entre España y los Países Bajos y problemas de los préstamos holandeses (flamencos) en castellano», En: Revista de filología española, 55:3/4, Madrid: 1972, pág. 240.
} 
G.J. Geers ${ }^{13}$ el término pichelingues (con sus posibles variantes pechelingues, pichlinges, pechilingues) aparece ya en obras de Lope de Vega (antes de 1604), Tirso de Molina y Jerónimo Barrionuevo con el significado de pirata, corsario y ladrón neerlandés. Sin embargo, el autor Geers, le atribuye otro origen etimológico a este término. Él propone que proviene del español pichel 'especie de jarra para beber que solía tener tapa' más el sufijo neerlandés -ing y que se identificaría en un principio con los neerlandeses, considerados unos borrachos, y más tarde con el estereotipo de neerlandés pirata:

\begin{abstract}
El que los soldados y los marineros españoles hayan conocido en los Países Bajos el sufijo -(l)ing es tan probable como cierto que poetas populares de Holanda como Breero (siglo XVII) y Speenhof (siglo XX) han sabido emplear sufijos y sonidos españoles... Ahora bien, para los españoles una de las particularidades más prominentes de los flamencos, holandeses, alemanes, etc., era su intemperancia en el beber, de modo que "bebedores, borrachos" era un invectivo muy a propósito. Esta formación caprichosa se habrá olvidado pronto y así la palabra pudo ser nombre para los holandeses y su cualidad más odiosa, la de la piratería. ${ }^{14}$
\end{abstract}

- urca 'un barco grande que sirve para el transporte de grano y otros enseres' <neerl. medio hulke. Actualmente en neerlandés el término se registra como hulk y se utiliza únicamente como término literario.

Aunque los Países Bajos históricos estuvieran en conflicto con España durante este período, el comercio español continúa con los Países Bajos en su propio territorio y en las colonias. Esto se desprende

${ }^{13}$ G.J. Geers, «Relaties tusschen Nederlandsch en Spaansch.», En: Handelingen van het Veertiende Nederlandsche Philologen-Congres, Groningen: J.B. Wolters, 1931, pág. 43.

${ }^{14}$ G.J. Geers, «Picaro, flamenco, pichelingue.», En: Mélanges de philologie à J.J. Salverda de Grave, Groningen: Wolters, 1933, pág. 134-137.

Futhark 6 (2011)

Sánchez, Intercambio Lingüístico,

225-253

ISSN 1886-9300 
de los términos náuticos españoles encontrados en la lengua neerlandesa:

- aviso "barco de guerra de menor envergadura para llevar noticias y comunicaciones' <esp. aviso.

- $\quad$ casco <esp. casco.

- cargo 'mercancía de un barco' <esp. cargo.

- dukdalf <esp. Duque de Alba. Hay dos posibles teorías de su origen etimológico. En primer lugar el Etymologisches Wörterbuch der deutschen Sprache aclara el siguiente origen etimológico:
Im Jahr, nachdem Herzog Alba 1567 niederländ.
Boden betreten hat, erscheint in dem ihm anhängenden Amsterdam duc Dalba für 'Pfahlgruppen, die zur Befestigung von Schiffen in den Hafen eingerammt sind'. ${ }^{15}$

Por lo tanto, el término neerlandés dukdalf es posible que tenga origen en la deformación del español duque de Alba. El Groot Woordenboek der Nederlandse Taal op CD-ROM ${ }^{16}$ también está de acuerdo con esta teoría. El Etymologisches Wörterbuch der deutschen Sprache ofrece el otro posible origen, apoyado también por Das große Wörterbuch der deutschen Sprache:

$$
\begin{aligned}
& \text { Vermutlich zu dallen "Pfähle" und ducken "sich } \\
& \text { neigen" (auch "tauchen") als "geneigte Pfähle" } \\
& \text { oder "eingetauchte Pfähle". Schon früh erklärt als } \\
& \text { Bezug auf den Herzog Alba (Duc d'Alba) für } \\
& \text { "Pfahlgruppe, die zur Befestigung von Schiffen in } \\
& \text { den Hafen eingerammt ist" in dem dem Herzog }
\end{aligned}
$$

\footnotetext{
${ }^{15}$ Friedrich Kluge, Etymologisches Wörterbuch der deutschen Sprache, Berlin: Walter de Gruyter, 1963, pág. 145.

${ }^{16}$ Cfr.: VVAA., Groot Woordenboek der Nederlandse Taal op CD-ROM. Plus versie 1.0., op. cit., 2000.
} 
anhängenden Amsterdam. Dies ist aber sicher sekundär. ${ }^{17}$

- $\quad$ patas 'un tipo de embarcación para llevar noticias o vigilar la entrada de una bahía' <esp. patache.

- $\quad$ armada <esp. armada.

- supercargo 'el que cuida la carga de un buque' <esp. sobrecargo.

- enteren 'abordar un barco enemigo' <esp. entrar.

- $\quad$ passaat <esp. (viento de) pasada.

- $\quad$ karviel 'un tipo de polea' <esp. cabilla

- traven 'estibar' <esp. trabar.

Además, los Países Bajos seguían destacando en esta época en la industria de la pesca ya que poseían una flota de pesca de entre 40.000 y 50.000 barcos, que en su mayoría se dedicaban a la pesca del arenque y la ballena en el mar del Norte. En el año 1385 un pescador de la provincia neerlandesa de Zelanda descubrió el procedimiento de la técnica de conservación del arenque, y desde entonces buena parte de la población neerlandesa se dedicó en los siglos siguientes a su captura, salazón y ahumado. ${ }^{18}$ La industria más importante de conservación y transformación del pescado se desarrolló en torno a los pueblos del Zuiderzee. Aunque otros países también se dedicaban a la pesca del arenque, sólo el neerlandés había conseguido un nivel de producción masivo y se había modernizado con nuevas técnicas. El navegante neerlandés Willem Barents descubrirá la isla de Spitzbergen (Noruega) en el año 1596, hecho que abre el camino para alcanzar nuevas zonas septentrionales aptas para la caza de ballenas en el Ártico. Tanto en la isla de Spitzbergen como en la de Jan

17 Friedrich Kluge, Etymologisches Wörterbuch der deutschen Sprache auf CD-ROM, Berlin: Walter de Gruyter, 1963, pág. 145.

${ }^{18}$ Cfr.: José Alcalá-Zamora y Queipo de Llano, España, Flandes y el Mar del Norte (16181639), Madrid: Centro de estudios políticos y constitucionales, 2001, pág. 59. 
Mayen, los neerlandeses cazaron unas 10.000 ballenas durante el período 1679-1688 y para ello emplearon unos 260 barcos con más de 14.000 marineros. ${ }^{19}$

Los Países Bajos, en su afán de ganar territorio al mar, comenzaron a construir un gran número de diques. El español toma prestada esta palabra del neerlandés dijk. El investigador Vidos aclara que no hay problema en el paso de la pronunciación neerlandesa del término dijk al español dique:

\begin{abstract}
La pronunciación de la palabra holandesa dijk, con el diptongo èy no ofrece dificultad alguna, porque se pronunció con una $i$ larga hasta finales de la Edad Media en holandés y tal se pronuncia aún hoy en los dialectos de la Holanda oriental. ${ }^{20}$
\end{abstract}

En los Países Bajos las dunas también actúan como diques y son además necesarias por estar una gran parte del territorio bajo el nivel del mar. En español se registra el préstamo neerlandés duna <neerl. duin. El Diccionario crítico etimológico castellano e hispánico ${ }^{21}$ aclara que algunos autores creen que se tomó directamente durante la Guerra de Flandes y otros investigadores opinan que pasó al español indirectamente a través del francés, que a menudo emplearían los flamencos para entenderse con los españoles. Los neerlandeses utilizaron también estos diques y dunas como estrategia militar para inundar algunos territorios y ciudades para que los españoles no pudieran acceder o simplemente se ahogaran. Igualmente utilizaron el marrazo ('pantano' <neerl. moeras) como elemento defensivo. Según Robert. A. Verdonck, este término sólo se utilizó con el significado añadido de 'pantano' en el español hablado en Flandes y nunca llegó a registrarse en el español peninsular, donde ya existía el étimo sólo con

${ }^{19}$ Cfr.: E.C., LLEWELLYN, The Influence of Low Dutch on the English Vocabulary, London: Oxford University Press, 1936, pág. 98.

20 Benedek Elémer Vidos, "Relaciones antiguas entre España y los Países Bajos y problemas de los préstamos holandeses (flamencos) en castellano», En: Revista de filología española, 55:3/4, Madrid, 1972, pág. 236.

${ }^{21}$ Cfr.; Joan Coromines / José A. Pascual. Diccionario crítico etimológico castellano e hispánico, 1ae ed., Madrid: Gredos, 1991-1992, vol. II, pág. 535. 
la acepción de "hacha de dos bocas que usaban los soldados para hacer leña'.22

Desde el siglo XV se conocían ya las técnicas de desecar terrenos con molinos de viento, dando lugar a los llamados pólder (<neerl. polder) ${ }^{23}$. Pero no será hasta el siglo XVI cuando se da un auge de estas desecaciones y una mejoría de estas técnicas apoyadas por la construcción de diques. ${ }^{24}$

Referido también al campo semántico de la arquitectura aparece en la lengua española el étimo hornabeque (<neerl. hoornwerk 'un tipo de fortificación exterior'). Solamente el investigador Robert A. Verdonck ${ }^{25}$ ofrece un origen neerlandés, mientras que todas las fuentes españolas utilizadas le dan un origen alemán: Hornwerk. Robert A. Verdonck llega a la conclusión de que el préstamo neerlandés hornabeque empezó ya a utilizarse en el español de Flandes entre 1627 y 1641, pero no llegó a utilizarse en el español de la Península hasta el año 1675. Todo lo demuestra con el hallazgo de fuentes que están escritas por autores flamencos que escribieron en lengua española en la región de Flandes. Por lo tanto, descarta el origen alemán de Joan Coromines que determina la fecha de primera aparición en 1709.

Bajo Felipe II se abrieron nuevas perspectivas para la mano de obra especializada de los Países Bajos. La política de construcción que la corte siguió en los primeros años de su gobierno atrajo a numerosos artesanos flamencos a España. La corte sirvió una vez más de motor para la inmigración desde Flandes. En 1563 empezaron las obras de construcción del Escorial y Felipe II trajo a jardineros flamencos para trabajar en él. En la construcción del palacio trabajaron albañiles, vidrieros y canteros flamencos que construyeron los techos y los dos

${ }^{22}$ Vid. Robert A. Verdonk, La lengua española en Flandes en el siglo XVII, Madrid: Insula, 1980, pág. 132.

${ }^{23}$ El término español pólder es un préstamo que todavía no está fechado en ninguna de las fuentes españolas consultadas, pero puede incluirse en este período analizado ya que los españoles tuvieron que conocer en esta época la técnica de desecar el terreno y su denominación.

${ }^{24}$ Cfr.: Jonathan I. Israel, De republiek 1477-1806, Franeker: Van Wijnen, 2001, pág. 119.

${ }^{25}$ Vid. Robert A. Verdonk, La lengua española en Flandes en el siglo XVII, Madrid: Insula, 1980, pág. 123-129.

Futhark 6 (2011)

Sánchez, Intercambio Lingüístico,

225-253

ISSN 1886-9300 
carrillones del Escorial. ${ }^{26} \mathrm{El}$ neerlandés toma prestado el siguiente léxico español enmarcado dentro del campo semántico de la arquitectura: alhidade 'instrumento de topografía' <esp. alidada; fenteneel <esp. ventanilla.

A pesar de todo lo dicho, el odio creado por la guerra y la percepción de ocupación ${ }^{27}$ española que tenían los neerlandeses dan lugar a la utilización de insultos, expresiones e interjecciones en neerlandés a partir de préstamos directos españoles:

- $\quad$ maraan <esp. marrano. Se recoge actualmente en el Groot Woordenboek der Nederlandse Taal op CD-ROM ${ }^{28}$ con dos significados: 1) insulto hacia los españoles durante la 'Guerra de los ochenta años' y 2) con el significado de 'converso que judaizaba ocultamente'. Según Eddy Stols "se establecía una correlación entre españoles y la falsa apariencia... por la cual se designaba también a todos los españoles de maraen o de falso cristiano." 29

- $\quad$ spanjool <esp. español. En sentido despectivo hacia un español.

- $\quad$ pagadder <esp. pagador. A partir de 1570 este término adquiere según el Woordenboek der Nederlandsche Taal en un principio dos significados. En primer lugar, es el término histórico para referirse al que pagaba los sueldos en el ejército. La palabra ha caído en desuso: "Eene in de 16de eeuw van de Spanjaarden overgenomen benaming,

${ }^{26}$ Vid. Werner Thomas/ Eddy Stols, «La integración de Flandes en la Monarquía Hispánica», En: Encuentros en Flandes, Leuven: Leuven University Press, 2000, pág. 53.

${ }^{27}$ En la mayoría de la bibliografía neerlandesa se utiliza el término bezetting, que se traduce al español como 'ocupación'. En la historia neerlandesa se entiende este período como una ocupación por parte de España.

${ }^{28}$ Cfr.: VVAA., Groot Woordenboek der Nederlandse Taal op CD-ROM. Plus versie 1.0., op. cit., 2000.

${ }^{29}$ Eddy Stols, "Gustos y disgustos en la confrontación y el intercambio alimenticios entre España y Flandes (siglos XVI y XVII)», En: Ana Crespo Solano y Manuel Herrero Sánchez, España y las 17 provincias de Los Países Bajos, Córdoba: Universidad de Córdoba, 2000, pág.596. 
inzonderheid voor den betaalmeester bij het leger." ${ }^{30} \mathrm{Y}$ en segundo lugar es un insulto hacia los españoles: “...., ook voor; slechten betaler en in 't algemeen voor: slecht volk gebruikt." ${ }^{31}$ Hoy en día pagadder ha cambiado de significado y tiene un uso regional: 'snaak' (bromista, guasón), 'kleinkind' (niño pequeño), y también como denominación para los habitantes no autóctonos de la ciudad de Amberes.

- $\quad$ machochel <esp. muchacha. Se recogió en 1599 como machache, machachel. Según el Etymologisch woordenboek ${ }^{32}$ se supone que fue tomado de las tropas españolas durante la Guerra de los ochenta años y que proviene de la palabra española muchacha. Hoy en día aparece en neerlandés con el significado de 'muchacha fea y gorda' y también con la acepción de 'cierta pera gorda y redonda'. En 1720 se registra en neerlandés un derivado de machochel: pieremachochje (spelen) ${ }^{33}$ 'hacer el amor', que es una palabra compuesta de pieren 'jugar' más machochel 'muchacha'. A partir de 1926 se encuentra pieremachochel con la acepción de 'mujer fea, barco viejo a la deriva'.

- $\quad$ parlesanten <esp. por los santos; basta <esp. ;basta!.

Sin embargo, en español sólo aparece un único insulto con procedencia neerlandesa. Es un préstamo histórico: gaznápiro. El $D R A E$ ofrece al respecto un origen incierto y el siguiente significado: "palurdo, simplón, torpe que se queda embobado con cualquier cosa". Joan Coromines lo considera también de origen incierto, pero da la posible teoría de que pueda provenir del término neerlandés gesnapper

30 VVAA., Groot Woordenboek der Nederlandsche Taal op CD-ROM, Rotterdam: Sdu Uitgeverij, 2000: (Trad.) "Denominación tomada de los españoles en el siglo XVI, especialmente para el que pagaba los sueldos en el ejército en el siglo XVI."

31 Ibíd. (Trad.): “..., y también utilizado para una persona que no paga (o que paga mal) y en general utilizado para una nación mala."

32 P.A.F. van Veen y Nicoline van der Sijs. Etymologisch woordenboek: de herkmost van onze woorden. Utrecht, Van Dale, 1997, pág. 529.

33 Ibíd, pág. 665. 
(una palabra que no existe actualmente) debido a una mezcla de las voces neerlandesas gesnap (parloteo, charla; hoy en día en desuso) y snapper (charlatán), confundidas por los soldados españoles de Flandes durante los siglos XVI y XVII. Dicho autor cree que gesnapper quizás no cuadre con las reglas ortográficas del neerlandés, pudiendo haberlo creado los españoles confundiendo los dos términos anteriormente citados. ${ }^{34}$

Este odio a causa de la ocupación española lleva a que los neerlandeses utilizaran una novedad para la guerra: los panfletos. En estos aparece la imagen del español cruel, avaro, guerrero e intolerante, sobre todo por las atrocidades llevadas a cabo por la Inquisición. Posteriormente, en el siglo XIX, llegó a registrarse en la historiografía oficial neerlandesa con la denominación de 'leyenda negra española'35. Por otra parte, la imagen de los neerlandeses por parte de los españoles era de hombres violentos, borrachos, herejes y piratas. De aquí, que se registren estos préstamos históricos en la lengua neerlandesa en el siglo XIX, aunque se refieren a este período al que hemos limitado el presente artículo:

- amigo <esp. amigo. El término amigo empleado en Flandes, concretamente en la región de Brabante, tiene el significado de 'gevangenis' (cárcel). Así se registra por ejemplo, en la actualidad en un diccionario flamenco-neerlandés: "De agenten hebben zojuist een Afrikaanse vrouw in de amigo opgesloten... [Humo, 26-02-2002]." ${ }^{36}$ En el 'middelnederlands' (neerlandés medio) existía el término vruunte, en un principio con el

${ }^{34}$ Joan Coromines / José A. Pascual. Diccionario crítico etimológico castellano e hispánico, op. cit., 1991-1992, Vol.III, pág. 140.

${ }^{35}$ Para más información al respecto véase la siguiente bibliografía: 1) Yolanda Rodríguez Pérez, De Tachtigjarige Oorlog in Spaanse Ogen, Nijmegen: Vantilt, 2003, pág 161-167 ; 2) Werner Thomas/ Eddy Stols, "La integración de Flandes en la Monarquía Hispánica», En: Encuentros en Flandes, Leuven: Leuven University Press, 2000, pág. 58-59; 3) Yolanda Rodríguez Pérez, "Los neerlandeses en el teatro de la primera fase de la Guerra de Flandes (1568-1609)», En: Ana Crespo Solana/Manuel Herrero Sánchez (coords.), España y las 17 provincias de los Países Bajos, Córdoba: Universidad de Córdoba, 2002, pág. 813.

36 VVAA., Vlaams-Nederlands Woordenboek. Antwerpen/Utrecht: Standaard/ Het Spectrum, 1997, pág. 30: (Trad.) "Los agentes acaban de encerrar a una señora africana en la cárcel... [Humo, 26-02-2002]." 
significado de 'posesión del señor' y más tarde con la acepción de 'cárcel del señor'. En algunos dialectos del sur de los Países Bajos, entre los que se incluye el dialecto de Brabante, la grafía <uu> se pronuncia [i:], y por lo tanto la palabra vruunt se pronuncia [vri:nt], coincidiendo así con la pronunciación del término neerlandés vriend [vri:nt], que se traduce en español por 'amigo'. Los españoles asentados entonces en Flandes durante el reinado español tradujeron la palabra vruunt por amigo, al oírlo como la pronunciación de la palabra neerlandesa vriend, y utilizaron la palabra amigo también con el significado de 'cárcel'. Los neerlandeses aplicaron a su vez el término amigo también a 'cárcel' al oírlo de los españoles.

- autodafe 'quema de un hereje' <esp. auto de fe.

- sanbenito 'escapulario para penitente' <esp. sambenito. Este mismo préstamo se registra ya en la lengua inglesa en el año 1655.

- hermandad 'policía' <esp. hermandad.

Con respecto a los aspectos económicos de este período, hay que destacar la fundación de la Bolsa de Ámsterdam (1608) que permitió una mayor agilidad comercial, ya que las compañías emitían acciones y se podía negociar con ellas. En el Banco de Ámsterdam se guardaban 300 millones de florines en oro en 1648, siendo la riqueza monetaria tan grande que el tipo de interés no subía del $3 \%$. En la lengua española se recogen los siguientes préstamos neerlandeses referidos al campo semántico de la economía:

- bolsa ${ }^{37}$ 'institución económica' <neerl. Van der Beurs. Antiguamente los mercaderes se reunían en un edificio para hablar y tratar sobre las mercancías. El Groot Woordenboek der

37 DRAE y DUE ofrecen ambos un origen directamente a través del neerlandés con la acepción segunda de 'casa de contratación'. Joan Coromines plantea un origen indirecto a través del italiano.

Futhark 6 (2011)

Sánchez, Intercambio Lingüístico,

225-253

ISSN 1886-9300 
Nederlandse Taal expresa lo siguiente: 'handelsbeurs' stamt van het huis de Beurs in Brugge, van de familie Van der Beurs." ${ }^{38}$ Por lo tanto, el apellido de esta familia pasó a denominar a la bolsa económica. En el escudo de la familia Van der Beurs aparecían tres pequeñas sacas o bolsas de dinero, ya que el término neerlandés beurs significa 'bolsa de dinero, monedero'. ${ }^{39}$

- guelte 'dinero, bienes' <neerl. geld. El DRAE crea la duda de si proviene del alemán o neerlandés geld. El Diccionario crítico etimológico castellano e hispánico defiende que procede del neerlandés: "lo aprenderían los soldados españoles en Flandes; luego vendrá del neerlandés antes que del alemán." 40 También existía la variante gueltre, mencionando el DRAE que su origen es la palabra alemana Gelder (plural dineros).

- cárolus <neerl. carolusgulden 'florín de Carlos'. Únicamente se registra en el $D R A E^{41}$ y es una moneda flamenca que se usó en España en tiempos de Carlos V. Podía ser de oro o plata y tenía un valor de 20 'stuivers' (duros). Luego se abrevió y dio lugar sólo a gulden, moneda oficial de los Países Bajos antes de la entrada del euro.

Con el intercambio comercial se introducen en la lengua neerlandesa dos nuevas monedas:

- patakon <esp. patagón. Llamado también en neerlandés Brabantische rijksdaalder. El patakon fue una moneda de plata que circuló en los Países Bajos durante los siglos XVII y XVIII.

${ }^{38}$ VVAA., Groot Woordenboek der Nederlandse Taal op CD-ROM. Plus versie 1.0., op.cit., 2000: (Trad.) "La bolsa del comercio procede de la casa 'de Beurs' en Brujas, de la familia Van der Beurs".

${ }^{39}$ Cfr.: P.A.F. van Veen /Nicoline van der Sijs . Etymologisch woordenboek: de herkomst van onze woorden, op. cit., (1르 publ. 1989)1997, pág. 93.

${ }^{40}$ Joan Coromines / José A. Pascual. Diccionario crítico etimológico castellano e hispánico, $1^{\text {a }}$ ed., Madrid: Gredos, 1991-1992, Vol. III, pág. 257.

${ }^{41}$ AAVV, Diccionario de la lengua española. Real Academia Española. CD-ROM versión 1.0., op. cit., 2003. 
- dubloen <esp. doblón.

El auge de la economía de un país va siempre asociado al número de transacciones comerciales. Es por ello que la anexión de Portugal a España por Felipe II acabó de dar el impulso decisivo al comercio neerlandés. Si hasta entonces los neerlandeses habían obtenido las especias y productos del Extremo Oriente en Lisboa, a partir de aquel momento fueron a buscarlas directamente a la India y a las islas del océano Índico. Así se explica la formación de la Compañía neerlandesa de las Indias Orientales en 1602. La flota mercante neerlandesa era en aquel momento la primera del mundo, y sus puertos los más concurridos, pues no obligaban a pagar derechos de entrada a diferencia de otros. Las relaciones de la Compañía de las Indias Orientales alcanzaban, en la época de su mayor extensión en el siglo XVII, desde el Cabo de Buena Esperanza hasta el Japón y Australia. En 1609 España declaró la Tregua de los Doce Años con los Países Bajos, pero Felipe III rompió la tregua por el miedo a que España pudiera perder su dominio en América. Los actos piratas neerlandeses continúan y el barco Nueva España es atacado en el año 1628 en las costas de Cuba por el famoso pirata holandés Piet Heyn con un botín de plata valorado en 12 millones de florines que es llevado a las Provincias Unidas para financiar la guerra contra España. ${ }^{42}$ La Compañía de las Indias Occidentales neerlandesas obtuvo las dos terceras partes de los beneficios del corso. Entre 1622 y 1636, sus 800 barcos de guerra y 67.000 marineros capturaron 547 navíos enemigos.

Así, tanto en tiempos de paz como en los de hostilidad, se intercambian términos del campo semántico de las plantas y los animales. En neerlandés en su mayoría son términos de procedencia española que designan productos que se extraen de las plantas o se elaboran a partir de ellas: indigo 'un tinte para los tejidos' <esp. índigo; kurk <esp. corcho; seroen 'una espuerta grande' <esp. serón; trens <esp. trenza. En español se registran los siguientes préstamos neerlandeses:

${ }^{42}$ Geoffrey Parker, El ejército de Flandes y el Camino Español 1567-1659, Madrid: Alianza Editorial, 2003, pág. 299.

Futhark 6 (2011)

Sánchez, Intercambio Lingüístico,

225-253

ISSN $1886-9300$ 
- guadapero (<flamenco wald-peer, peral silvestre). El Diccionario crítico etimológico castellano e hispánico no está de acuerdo con este origen:

Supone el DRAE que guadapero venga del flamenco waldpeer, lo cual no es posible, porque en el s. XV, cuando escribía Nebrija, no había habido contactos directos entre España y Flandes. ${ }^{43}$

Esta afirmación de Joan Coromines contrasta con las fuentes neerlandeses utilizadas en esta investigación, ya que en la lengua neerlandesa sí se registran préstamos españoles directos anteriormente al año 1496 como, por ejemplo: tint (1382) <esp. tinto, riem (1384) <esp. resma, cargadoor (1472) <esp. cargador, realgar (1305) <esp. rejalgar. ${ }^{44}$ Por lo tanto, no hizo falta que los Países Bajos históricos pertenecieran a la corona Española (a partir del año 1496) para que aparecieran préstamos directos neerlandeses en español. Antes de esta fecha también hubo contactos entre comerciantes españoles y flamencos. El investigador B.E. Vidos realiza una buena descripción histórica de estas primeras relaciones:

Las relaciones entre España y los Países Bajos se inician a partir del siglo XII en que marineros y comerciantes flamencos, holandeses y frisones zarpan de los puertos del Mar del Norte con sus buques cargados de mercancías, en especial tejidos, con destino a la Península Ibérica, y

${ }^{43}$ Joan Coromines / José A. Pascual. Diccionario crítico etimológico castellano e hispánico, 1ª ed., Madrid: Gredos, 1991-1992, Vol. III, pág. 236.

${ }^{44}$ Véase los términos en el Groot Woordenboek der Nederlandsche Taal (WNT), 'SGravenhage: Sdu, 1993. La palabra española rejalgar posee actualmente la acepción de 'combinación venenosa de arsénico y azufre'. El término realgar se recogió en neerlandés en el año 1305 con el significado de 'veneno de rata' a partir de un mineral, y que quizás se utilizara para erradicar las plagas de ratas. Actualmente en la lengua neerlandesa este préstamo ha ampliado su significado, pues el mineral también es utilizado para curtir pieles y obtener el fuego blanco de los fuegos artificiales. 
asimismo como consecuencia de las Cruzadas y de las peregrinaciones a Santiago de Compostela. ${ }^{45}$

- olivarda <neerl. alantswortel 'raíz de alant (énula)'. Corresponde a una planta de la familia de las compuestas. Se ha empleado como astringente y cicatrizante.

- té $<$ neerl. thee 'té' <mal. te $(h)<$ chino t'e. Friedrich Kluge expresa el origen etimológico de esta planta:

Der Tee wurde 1610 von der Ostindisichen Companie nach Europa gebracht, war aber als Exotismus schon seit dem 10. Jh. bekannt. Die Entlehnungen mit Anlaut t- gehen auf diese Vermittlung des Niederländischen zurück, während die Wörter mit Anlaut tsch- (port., russ. und andere slawische Sprachen) auf die normale chinesische Form zurückgehen. ${ }^{46}$

Con respecto al campo semántico de los animales aparecen los siguientes préstamos españoles en la lengua neerlandesa:

- ansjovis <esp. anchoa. El término neerlandés ansjovis deriva del término español anchoa, al que se le ha añadido en neerlandés por etimología popular vis 'pez, pescado'.

- albikoor 'un tipo de pez' <esp. albacora.

- bezoar <esp. bezoar. Es una especie de cálculo que se encuentra en el estómago o los intestinos de los rumiantes y que antiguamente se utilizaba como antídoto contra todo tipo de venenos, especialmente el arsénico.

45 Benedek Elémer Vidos, «Relaciones antiguas entre España y los Países Bajos y problemas de los préstamos holandeses (flamencos) en castellano", Revista de filología española, 55:3/4, Madrid, 1972, pág. 233.

${ }^{46}$ Friedrich Kluge, Etymologisches Wörterbuch der deutschen Sprache auf CD-ROM, Berlin: Walter de Gruyter, 2002.

Futhark 6 (2011)

Sánchez, Intercambio Lingüístico,

225-253

ISSN $1886-9300$ 
- $\quad$ kavalje <esp. caballejo. Este último término kavalje ${ }^{47}$ se registró en 1599 con el significado de 'oud paard, oud huis' (caballo viejo, casa vieja). Actualmente se recoge en la lengua neerlandesa con el significado añadido de 'oude, onaantrekkelijke vrouw' (mujer vieja y sin atractivo).

Sin embargo, en español sólo se registra un único préstamo español referido a este campo semántico: estocafís <neerl. medio stokvisch 'un tipo de bacalao'. Hoy en día en neerlandés se recoge como stokvis. Es una palabra compuesta de dos partes: stok 'bastón, palo' y vis 'pez'. Era un pez que se curaba sobre palos.

A principios del siglo XVI Amberes comenzó a importar azúcar de las Islas Canarias que fue el principal cultivo desde la anexión a la corona de Castilla a finales del siglo XV. Se trataba de una materia prima que ofreció bastante trabajo a los refinadores. ${ }^{48}$ De ahí que en neerlandés se registra el préstamo raffinaderij <esp. refinador. Así, otro término perteneciente al campo semántico de la agricultura que se tomó prestado fue el préstamo peon <esp. peón. La sal de Sanlúcar de Barrameda sirvió a los neerlandeses para el adobo de pescado y carne y el avinagrado de productos lácteos, mientras que el aceite de oliva de Sevilla fue utilizado para el abatanado del tejido y la jabonería. De Jerez de la Frontera y el Puerto de Santa María se cargaban en barcos vino, naranjas y limones hacia Flandes. ${ }^{49}$

Dejando a un lado la economía y el comercio, veamos qué ocurre con la literatura. En el siglo XVII se leían en los Países Bajos históricos las obras traducidas al neerlandés de Cervantes, Lope de Vega y Calderón de la Barca. Aparece en esta época ya la primera alusión a la literatura española extraída del Quijote: rossinant <esp. rocinante. Otros préstamos históricos literarios aparecen posteriormente, aunque éstos

47 P.A.F. van Veen y Nicoline van der Sijs. Etymologisch woordenboek: de herkomst van onze woorden. Utrecht: Van Dale, 1997, pág. 448.

${ }^{48}$ Ana Viña Brito, «El azúcar canario y la cultura flamenca. Un viaje de ida y vuelta», En: Ana Crespo Solano/Manuel Herrero Sánchez, España y las 17 provincias de los Países Bajos, Córdoba: Universidad de Córdoba, 2002, pág. 619.

49 Vid. Werner Thomas/ Eddy Stols, «La integración de Flandes en la Monarquía hispánica», En: Encuentros en Flandes, Leuven: Leuven University Press, 2000, pág. 29. 
deberían haberse conocido anteriormente: dulcinea <esp. Dulcinea, hidalgo <esp. hidalgo, caballero <esp. caballero, picaro <esp. pícaro. Según Eddy Stols, en los Países Bajos se difunde la imagen de una España hambrienta, idea confirmada en pasajes de las obras de Cervantes y en las novelas picarescas como El Lazarillo de Tormes, que también fue traducida al neerlandés. Así, Eddy Stols, comenta lo siguiente:

En La Vida y los actos del perro del duque de Alba, publicada en Ámsterdam en 1658 como una chanza del Coloquio de los perros de Cervantes (1613), el perro Cipión cuenta sus vivencias y andanzas por España y se mofa de las costumbres alimenticias de sus habitantes. ${ }^{50}$

Al hilo de lo dicho, en el campo semántico de la comida destaca en la lengua neerlandesa el préstamo olipodriga (también se registra como olla podrida en neerlandés). Según la bibliografía neerlandesa, proviene de la palabra española olla podrida y se recoge con el significado de "uit Spanje afkomstige stoofpot" $"$. Como anécdota, el puchero español aparece registrado en una leyenda referida a la liberación de la ciudad de Leiden el 3 de octubre de 1574. Se cree que lo que estaban comiendo los españoles antes de la liberación era un puchero que se podría corresponder con la olla podrida:

De Leidse weesjongen Cornelis Joppens zou, aangetrokken door de geur, op de 'Schansse van Lammen' (het huidige Lammerschans) in een verlaten legerkamp van de Spanjaarden een nog warme pot hutspot gevonden hebben, wat het bewijs was dat de Spanjaarden gevlucht waren en Leiden dus bevrijd was. ${ }^{52}$

${ }^{50}$ Eddy Stols, "Gustos y disgustos en la confrontación y el intercambio alimenticios entre España y Flandes (siglos XVI y XVII)», En: Ana Crespo Solano y Manuel Herrero Sánchez, España y las 17 provincias de Los Países Bajos., Córdoba: Universidad de Córdoba, 2002, pág. 594.

51 P.A.F. van Veen y Nicoline van der Sijs. Etymologisch woordenboek: de herkomst van onze woorden, op. cit., 1997, pág. 612. (Trad.): "puchero proveniente de España".

${ }^{52}$ Nicoline van der Sijs. Chronologisch woordenboek, Amsterdam, uitgeverij C.J. Veen, 2001, pág. 254. (Trad.): "El niño huérfano de Leiden, Ilamado Cornelis Joppens, atraído por el olor, había encontrado una olla de puchero en un campamento militar abandonado Futhark 6 (2011)

Sánchez, Intercambio Lingüístico,

225-253

ISSN 1886-9300 
Hoy en día olipodriga se recoge en el Groot Woordenboek der Nederlandse Taal ${ }^{53}$ todavía con la acepción de una especie de 'puchero con carne, tocino y verduras', pero también con el significado figurado adicional de 'mengelmoes, poespas, allegaartje' (mezcolanza o conjunto de ideas raras), que recuerda a la composición extraña y variada de la olla podrida.

Con respecto a las bebidas se registran en neerlandés los siguientes préstamos españoles:

- $\quad$ madera 'vino de la isla de Madeira' <esp. madera.

- kanariesek 'un tipo de vino' <esp. seco. La primera parte kanarie proviene de Islas Canarias y sek del término español seco.

En sentido inverso, la introducción de alimentos de los Países Bajos históricos fue menor en España. Estos productos se destinaban a las tripulaciones y a los bodegueros flamencos que en su mayoría se establecieron en Cádiz. En el siglo XVI se estableció en Sevilla una colonia de aproximadamente trescientos flamencos y fundaron su propia cofradía. ${ }^{54}$ Lo mismo sucedió en Málaga. Estos colonos importaban cantidades limitadas de arenque y salmón salado, queso y cerveza.

\section{Préstamos del Nuevo Continente}

El descubrimiento de nuevos territorios por parte de España en América trae el hallazgo de nuevos animales y plantas hasta entonces desconocidos en Europa. La aparición de nuevas razas y sus mezclas también contribuye a la introducción de nuevos términos en la lengua neerlandesa:

a) Animales

por los españoles, situado dentro de 'Las Schansse van Lammen' [actualmente Lammerschans], lo que constituía la prueba de que los españoles habían huido y, por lo tanto, Leiden había sido liberada."

${ }_{53}$ Groot Woordenboek der Nederlandse Taal op CD-ROM. Plusversie 1.0., op. cit., 2000.

54 Cfr. Werner Thomas/ Eddy Stols, «La integración de Flandes en la Monarquía Hispánica», En: Encuentros en Flandes, Leuven: Leuven University Press, 2000, pág. 35. 
kaaiman <esp. caimán, toekan <esp. tucán, armadil <esp. armadillo, muskiet <esp. mosquito, ara 'tipo de papayo' <esp. ara, jabiroe 'una especie de cigüeña' <esp. jabirú, parkiet <esp. periquito $^{55}$, tapir <esp. tapir, vicuña <esp. vicuña; kolibrie <esp. colibrí,

b) Plantas

coca <esp. coca, bataat <esp. batata ${ }^{56}$, pataat <esp. patata, tabak $<$ esp. tabaco, maïs <esp. maíz, ananas <esp. ananás cacao <esp. cacao; papaja <esp. papaya; braziel <esp. brasil, kokosnoot <esp. coco, sassafras <esp. sasafrás; tomaat <esp. tomate; kopal <esp. copal 'resina de árbol' <esp. copal, sarsaparilla 'arbusto americano' <esp. zarzaparrilla [de Indias], cassave 'un tipo de harina' <esp. cazabe, pitte 'hoja de hilo' <esp. pita, orleaan 'un tipo de colorante extraído de un árbol' <esp. orellana, palissander $<$ esp. palosanto ${ }^{57}$, chocolade <esp. chocolate ${ }^{58}$, zonnebloem ${ }^{59}$ $<$ esp. girasol, yucca <esp. yuca.

c) Razas

55 Joan Coromines, Breve Diccionario Etimológico de la lengua castellana, Madrid: Gredos, 2008, pág. 425. El autor indica la siguiente etimología: "Del nombre propio de persona Perico, diminutivo de Pero (por Pedro), con el cual se llamaba al papagayo, por su charlar casi humano."

${ }^{56}$ Aunque los neerlandeses adoptaron también la confusión existente entre los términos españoles papa y batata dando lugar a patata, éstos utilizaban más la palabra aardappel, que ya existía con anterioridad al Descubrimiento y que designaba a la raíz del ciclamen (que tenía un aspecto similar al de la patata), utilizándose luego para denominar a la patata. Justamente después del año 1492 se conoció primeramente en España la batata y no será hasta 1530 cuando los españoles descubran la papa en los Andes.

${ }^{57}$ El neerlandés lo tomó de la corrupción del término español palo santo. Los españoles conocieron en América un tipo de árbol del que aprovecharon su madera y al que denominaron palo santo. Más tarde, los neerlandeses vieron en Surinam un árbol parecido y le llamaron con el mismo nombre, aunque eran plantas diferentes.

${ }^{58}$ El cambio consonántico de $t$ a $d$, se debe a la influencia del sufijo neerlandés -ade que existía anteriormente en neerlandés en términos como limonade, marmelade. Vid. Nicoline van der Sijs, Klein Uitleeenwoordenboek, Den Haag/Utrecht: SDU Uitgevers, 2006, pág. 44.

${ }^{59}$ Es un calco aproximado, ya que sol se ha traducido literalmente por zon, sin embargo gira se ha cambiado por bloem ('flor').

Futhark 6 (2011)

Sánchez, Intercambio Lingüístico,

225-253

ISSN 1886-9300 
El consiguiente asentamiento y los conflictos causados por España y otros países europeos en el continente americano provocaron que la población indígena disminuyera. La falta de la mano de obra autóctona originó la necesidad de traer esclavos negros procedentes de África. El comercio de la trata de esclavos había aumentado por la posesión de colonias en las Indias Occidentales de Inglaterra y los Países Bajos. Así destacará Curaçao (de las Antillas neerlandesas) por el cultivo del azúcar, el mercado de la sal (tras el embargo peninsular en el año 1598) y la madera. Los neerlandeses necesitaban mano de obra para las plantaciones allí, así que la isla se convirtió en uno de los principales mercados de esclavos para abastecer a todas las colonias europeas en el Nuevo Continente. ${ }^{60}$ La introducción de la raza negra en la América española estuvo controlada de modo indirecto por los comerciantes neerlandeses. Al mezclarse los europeos, los indígenas y la población negra procedente de África se crearon nuevas razas. Así, he encontrado los siguientes préstamos directos españoles que se introducen más tarde en la lengua neerlandesa: neger <esp. negro; mesties <esp. mestizo; mulat <esp. mulato.

De las tribus indígenas autóctonas del Nuevo Continente se registran en neerlandés los siguientes términos:

- kannibaal <esp. caníbal. Se recoge en neerlandés en el año 1566, y es una deformación de las palabras 'can' (perro) y 'Caribal' (indio del Caribe). Colón descubrió los caníbales en Puerto Rico. ${ }^{61}$ Otras fuentes, como el Etymologisch woordenboek van het Nederlands ${ }^{62}$, sostienen que el étimo procede del prefijo carib- que

${ }^{60}$ Carmen Sanz Ayán, «Financieros holandeses de Felipe V en la Guerra de Sucesión. Huberto Hubrecht», En: Ana Crespo Solano/Manuel Herrero Sánchez, España y las 17 provincias de los Países Bajos, Córdoba: Universidad de Córdoba, 2002, pág. 572.

${ }^{61}$ La afirmación de que la influencia de can y caribal dio lugar a caníbal aparece reflejado en: P.A.F. van Veen y Nicoline van der Sijs. Etymologisch woordenboek: de herkomst van onze woorden. Utrecht: Van Dale, 1997, pág. 440.

62 VVAA, Etymologisch woordenboek van het Nederlands, Amsterdam: Amsterdam University Press, 2003, Vol. F-Ka, pág. 623. 
significa 'valiente, poderoso' en las lenguas indígenas del Caribe. El paso de la consonate $r$ a $n$ sería por influencia de la lengua taína que los denominaban canibal en vez de caribal.

- cacique <esp. cacique. Hace alusión a las historias de un cacique llamado 'El Dorado': “de cacique (vorst-priester) van Guatafita in Colombia, die, met stofgoud bepoederd, zich op een heilig meer begaf om te offeren en zich daarin reinigde." ${ }^{63}$ Esto hizo que se creara la leyenda de que había países repletos de oro.

\section{d) Geografía}

- orkaan (1657) <esp. huracán. El término orkaan es tomado por los españoles de la palabra maya hunraken (Osa Mayor): "als de zon in het teken van de Grote Beer staat breekt het seizoen van de orkanen aan." 64

- tornado (1596) <esp. tornado

e) Navegación

- $\quad \boldsymbol{k a n o}(1598)<$ esp. canoa

f) Otros

63 J. De Vries. Etymologisch Woordenboek, 20ํdruk, Utrecht: Het Spectrum, 1997, pág. 126: (Trad.) "El cacique (jefe de una tribu india) de Guatafita en Colombia, cubierto con polvo de oro, se dirigía a un lago sagrado para ofrecer sacrificio y después purificarse en él."

${ }^{64}$ P.A.F. van Veen /Nicoline van der Sijs. Etymologisch woordenboek: de herkomst van onze woorden. Utrecht: Van Dale, 1997, pág. 627: (Trad.) "Cuando el sol está en la constelación Osa Mayor comienza la estación de los huracanes." 
- $\quad$ hangmat <esp. hamaca. Es una palabra que procede de la etimología popular formada a partir de otras dos: hangen 'colgar' y mat 'estera'. Friedrich Kluge aclara lo siguiente:

Schon Kolumbus lernt auf Haiti die
Schlafnetze der Eingeborenen kennen, die
diese mit einem karibischen Wort als hamáka
bezeichneten. Die Sache wird weithin
bekannt und dient zunächst als Vorbild für die
Schlafstellen der Matrosen. ${ }^{65}$

\section{Conclusiones}

Tras el análisis del intercambio lingüístico en el período 1496-1714 entre España y los Países Bajos históricos se deduce que la lengua neerlandesa ha tomado más préstamos del español que al contrario: un total de 22 préstamos neerlandeses en el español, mientras que en la lengua neerlandesa he hallado 53 préstamos españoles. Esto es debido a que la zona geográfica ocupada fueron los Países Bajos históricos y además el español contaba con un mayor número de hablantes que la lengua neerlandesa.

En términos absolutos, el campo semántico con un mayor de número de préstamos adscritos tanto en la lengua neerlandesa (11, un $21 \%$ del total) como en el español peninsular (9, un 40\%) es el de la navegación, ya que ambos países fueron potencias mundiales en aquel momento y poseían un gran conocimiento de los mares, además de un gran número y variedad de navíos. Como se observa, el campo semántico de la navegación agrupa casi la mitad de los vocablos neerlandeses prestados a la lengua española. En segundo lugar, se encuentra en ambas lenguas el campo semántico de los animales y plantas: 8 préstamos (15\% del total) y 4 en español (un $18 \%$ del total). $Y$ por último, en tercer lugar, se halla en neerlandés el campo semántico de los insultos/interjecciones, con una cantidad de 6 préstamos, lo que

${ }^{65}$ Friedrich Kluge, Etymologisches Wörterbuch der deutschen Sprache auf CD-ROM, op. cit., 2002. 
demuestra el contacto estrecho que hubo entre las dos lenguas en el período de la guerra de los Ochenta Años, ya que estos préstamos no son técnicos. Muy próximo por su número está el campo semántico militar con 5 préstamos. Sin embargo, en la lengua española el tercer puesto lo ocupan los campos semánticos de la economía y el de la arquitectura, ambos con 3 préstamos.

Con respecto a la influencia de préstamos procedentes de Hispanoamérica en el período 1496-1714, he registrado un total de 40 préstamos. El campo semántico con una mayor cantidad de vocablos es el de los animales/plantas con 31 préstamos, seguido del campo semántico de las razas, con 5 préstamos.

Ambos países se odiaban, uno acusado de cruel e inquisidor y el otro de pirata y hereje. Sin embargo, la leyenda negra y el conflicto bélico no interrumpieron el comercio y el intercambio cultural e intelectual, como queda reflejado en los préstamos encontrados en las dos lenguas.

\section{REFERENCIAS BIBLIOGRÁFICAS}

ALCALÁ-ZAMORA Y QUEIPO DE LLANO, JOSÉ, España, Flandes y el Mar del Norte (1618-1639), Madrid: Centro de estudios políticos y constitucionales, 2001.

COROMINES, JOAN / PASCUAL, JOSÉ A. Diccionario crítico etimológico castellano e hispánico, $1^{\text {a }}$ ed., Madrid: Gredos, 1991-1992.

CRESPO SOLANA, ANA/ HERRERO SÁNCHEZ, MANUEL, España y las 17 provincias de los Países Bajos: una revisión historiográfica (XVI-XVIII), Córdoba: Universidad de Córdoba, 2002.

GEERS, G.J., «Picaro, flamenco, pichelingue.», En: Mélanges de philologie à J.J. Salverda de Grave, Groningen: Wolters, 1933, pág. 132-138. 
«Relaties tusschen Nederlandsch en Spaansch.», En: Handelingen van het Veertiende Nederlandsche PhilologenCongres, Groningen: J.B. Wolters, 1931, pág. 43-45.

ISRAEL, JONATHAN, De Republiek 1477-1806. Franeker: Van Wijnen, 2001.

KLUGE, FRIEDRICH, Etymologisches Wörterbuch der deutschen Sprache auf CD-ROM, Berlin: Walter de Gruyter, 2002.

LLEWELLYN, E.C., The Influence of Low Dutch on the English Vocabulary, London: Oxford University Press, 1936.

MOLINER, MARÍA, Diccionario de uso del español en CD-ROM, Madrid: Gredos, 2007.

PARKER, GEOFFREY, El ejército de Flandes y el camino español, 1567-1659: la logística de la victoria y derrota de España en las guerras de los Países Bajos, Madrid: Alianza, 2003. , España y los Países Bajos, 1559-1659: diez estudios, Madrid: Rialp, 1986.

RODRÍGUEZ PÉREZ, YOLANDA, De Tachtigjarige Oorlog in Spaanse Ogen, Nijmegen: Vantilt, 2003.

SIJS, NICOLINE VAN DER, Chronologisch Woordenboek, Amsterdam: L.J. Veen, 2001. Geleend en uitgeleend. Amsterdam / Antwerpen: Het Taalfonds / Contact, 1998. , Groot Leenwoordenboek. De invloed van andere talen op het Nederlands. Utrecht/Antwerpen: Van Dale, 2005.

2006. Klein uitleenwoordenboek, Den Haag / Utrecht: SDU uitgevers, NEEN, P.A.F. VAN, Etymologisch woordenboek: de herkomst van onze woorden, Utrecht: Van Dale, 1997. (1를 imp. 1989).

THOMAS, WERNER/ VERDONK, ROBERT A. (eds.), Encuentros en Flandes. Relaciones e intercambios hispanoflamencos a inicios de la Edad Moderna, Leuven: Leuven University Press, 2000.

VALKHOFF, MARIUS F., De expansie van het Nederlands, Brussel: Manteau N.V., 1943. 
VAN DAM, C.F.A., "De spaanse woorden in het Nederlands.", En: Bundel opstellen van oud-leerlingen. Aangeboden aan Prof. Dr. C.G.N. de Vooys, Groningen: J.B. Wolters, 1940, pág. 86-103.

VAN DER HORST, HAN, Nederland. De vaderlandse geschiedenis van de prehistorie tot nu, Amsterdam: Prometheus, 2002.

VERDAM, J., Middelnederlandsch handwoordenboek, 's-Gravenhage: Martinus Nijhoff, (1 $1^{a}$ ed. 1911) 2002.

VERDONK, ROBERT A., La lengua española en Flandes en el siglo XVII, Madrid: Insula, 1980.

VIDOS, BENEDEK ELEMÉR, «Relaciones antiguas entre España y los Países Bajos y problemas de los préstamos holandeses (flamencos) en castellano», En: Revista de filología española, 55:3/4, Madrid, 1972, pág. 233-242.

VRIES, JAN DE, Etymologisch Woordenboek, Utrecht: Het Spectrum, 1997.

VVAA., Diccionario de la lengua española. Real Academia Española. CD-ROM versión 1.0., Madrid: Espasa, 2003.

VVAA, Etymologisch woordenboek van het Nederlands, Amsterdam: Amsterdam University Press, 2003

VVAA., Groot Woordenboek der Nederlandse Taal op CD-ROM. Plus versie 1.0., Utrecht /Antwerpen: Van Dale, 2000.

VVAA., Nuevo tesoro lexicográfico del español (S. XIV-1726), Madrid: Arco libros, 2007.

VVAA., Vlaams-Nederlands Woordenboek, Antwerpen/Utrecht: Standaard/ Het Spectrum, 1997.

VVAA., Woordenboek der Nederlandsche Taal op CD-ROM (WNT), Rotterdam: Sdu, 2003. 